\title{
Nutrientes e propriedades funcionais em sementes de abóbora (Cucurbita maxima) submetidas a diferentes processamentos
}

\author{
Nutrients and functional properties in pumpkin seed (Cucurbita maxima) submitted to different processings
}

Luciana de Paula NAVES ${ }^{1 \star}$, Angelita Duarte CORRÊA ${ }^{2}$, Celeste Maria Patto de ABREU², Custódio Donizete dos SANTOS ${ }^{2}$

\begin{abstract}
Resumo
O objetivo deste trabalho foi verificar a influência dos processamentos térmicos sobre os nutrientes e propriedades funcionais das sementes da abóbora Cucurbita maxima. As sementes foram, em quatro repetições, submetidas aos seguintes processamentos: utilizadas na forma crua; cozidas em água em ebulição por três tempos: 5, 10 e 15 minutos; e cozidas no vapor por 10 minutos. Posteriormente foram liofilizadas, trituradas e armazenadas em temperatura ambiente até a realização das análises de composição centesimal, minerais e propriedades funcionais. Não houve diferença significativa entre os processamentos para os níveis de proteína bruta, fibra alimentar, extrato etéreo, cinzas, $\mathrm{S}, \mathrm{P}, \mathrm{Mg}$, Ca, $\mathrm{Cu}, \mathrm{Zn}$, solubilidade do nitrogênio (nos pH 4, 5 e 6), absorção de água e óleo, volume de espuma e estabilidade de emulsão. O cozimento em água em ebulição reduziu o teor de $\mathrm{K}$. Todos os processamentos térmicos diminuíram os níveis de Mn e Fe. As sementes cruas apresentaram a maior solubilidade do nitrogênio nos $\mathrm{pH}$ 2, 3, 7, 8 e 9. Conclui-se que os processamentos acarretaram diferença significativa apenas nos teores de K, Mn, Fe e solubilidade do nitrogênio; e que as sementes apresentam potencial para serem incorporadas, provavelmente, em alimentos que requeiram elevada taxa de absorção de óleo.

Palavras-chave: Cucurbita máxima; semente de abóbora; processamento; nutriente; propriedade funcional.
\end{abstract}

\begin{abstract}
The objective of this paper was to verify the influence of the thermal processings on the nutrients and functional properties of the pumpkin seeds Cucurbita maxima. Seeds were, in four repetitions, submitted to the following processings: used in the raw form; cooked in boiling water for three times: 5, 10 and 15 minutes; and cooked in steam for 10 minutes. Thereafter were freeze-dried, grinded and stored at room temperature up to accomplishment of the analyses of centesimal composition, minerals and functional properties. There wasn't significant difference among the processings to the levels of crude protein, dietary fiber, ether extract, ashes, $\mathrm{S}, \mathrm{P}, \mathrm{Mg}, \mathrm{Ca}, \mathrm{Cu}, \mathrm{Zn}$, solubility of the nitrogen (on $\mathrm{pH} 4,5$ and 6), absorption of water and oil, foam volume and emulsion stability. The cooking in boiling water reduced content of K. All thermal processings reduced levels of $\mathrm{Mn}$ and Fe. Raw seeds showed biggest solubility of nitrogen on $\mathrm{pH} 2,3,7,8$ and 9 . It has been concluded that the processings caused significant difference only in levels of $\mathrm{K}, \mathrm{Mn}$, Fe and solubility of nitrogen; and that the seeds presents potential to be, probably, incorporated in foods that request high tax of absorption of oil.
\end{abstract}

Keywords: Cucurbita maxima; pumpkin seed; processing; nutrient; functional property.

\section{Introdução}

Durante as últimas décadas, a demanda por novos alimentos nutricionalmente saudáveis e economicamente viáveis aumentou consideravelmente. Consequentemente, muita atenção tem sido dada à utilização de subprodutos vegetais, em sua maioria, não utilizados pela indústria de alimentos nem pela população. A utilização desses subprodutos agrega valor econômico à produção, além de contribuir para a formulação de novos produtos alimentícios e minimizar o desperdício.

A abóbora Cucurbita maxima, popularmente conhecida como moranga, pertence à família Cucurbitaceae. É nativa das Américas e atualmente cultivada em grande escala no Brasil e em outras regiões tropicais. Somente no município de Ponte Alta Santa Catarina/Brasil, a safra de morangas colhidas no início de 2006 foi de 3600 t (ABH, 2008). Segundo Del-Vechio (2004),
$3,32 \%$ do peso da moranga corresponde ao peso das sementes, portanto, considerando apenas esse município, houve um descarte de aproximadamente 119 toneladas de sementes. Analisando esses dados, é possível reconhecer como é grande o desperdício, em escala nacional e internacional, das sementes da moranga.

Tais sementes são conhecidas principalmente pelo elevado teor proteico e de óleo. Em algumas regiões da África e do Brasil, por exemplo, são consumidas pela população carente como complemento alimentar. Na Grécia, são apreciadas em quantidades significativas, ao serem tostadas e salgadas (LAZOS; TSAKNIS; BANTE, 1995). Na Áustria, o óleo extraído da semente é aproveitado como tempero para saladas em função de seu aroma e gosto característicos (EL-ADAWY; TAHA, 2001b).

Recebido para publicação em 23/6/2008

Aceito para publicação em 6/1/2009 (003579)

${ }^{1}$ Departamento de Zootecnia, Universidade Federal de Lavras - UFLA, Minas Gerais, MG, Brasil, CP 3037 - CEP 37200-000, E-mail: luciana.naves@hotmail.com

2 Departamento de Química, Universidade Federal de Lavras - UFLA, Minas Gerais, MG, Brasil, E-mail: angelita@dqi.ufla.br'

${ }^{*}$ A quem a correspondência deve ser enviada 
Na medicina popular, são utilizadas como vermífugo, devido à ação anti-helmíntica que apresentam. Além disso, pesquisas toxicológicas com ratos mostraram que o extrato hidroalcoólico de sementes da moranga, na dose de $5000 \mathrm{mg} \cdot \mathrm{kg}^{-1}$, não acarreta toxicidade aguda e apresenta boa margem de segurança (CRUZ et al., 2006).

Embora haja o consumo dessas sementes em determinadas regiões do mundo, tal aproveitamento corresponde apenas a uma pequena parcela das sementes de moranga desperdiçadas cotidianamente. Para minimizar esse desperdício e agregar benefícios econômicos ao produtor da moranga e à indústria de alimentos, é necessário que as sementes sejam utilizadas em escala industrial.

O tratamento térmico dos alimentos é um procedimento culinário amplamente utilizado na indústria para melhorar a palatabilidade e a qualidade nutricional, entre outros. Entretanto é necessário assegurar que o processamento térmico aplicado seja adequado para garantir esses benefícios.

As propriedades funcionais são particularidades físicoquímicas dos alimentos que colaboram para que tenham as características desejadas pelo consumidor. Podem ser alteradas durante a preparação e processamento dos alimentos. Portanto, é indispensável à indústria de alimentos a caracterização dessas propriedades nos subprodutos que apresentam potencial para serem comercializados, assim como a avaliação do efeito dos processamentos sobre tais propriedades.

Atualmente, pouco se conhece sobre o efeito de processamentos térmicos nos níveis de nutrientes da semente da moranga, e menos ainda acerca de suas propriedades funcionais.

Portanto, o objetivo deste trabalho foi verificar a influência dos processamentos térmicos sobre os nutrientes e propriedades funcionais da semente da abóbora Cucurbita maxima.

\section{Material e métodos}

\subsection{Obtenção das abóboras e preparo das amostras}

Este trabalho foi desenvolvido no Laboratório de Bioquímica/Departamento de Química da Universidade Federal de Lavras/Minas Gerais/Brasil.

As abóboras Cucurbita maxima, popularmente conhecidas como moranga, foram obtidas no comércio varejista de hortifrutigranjeiros de Lavras. Elas foram lavadas em água destilada, sanitizadas com hipoclorito de sódio $200 \mathrm{mg} . \mathrm{L}^{-1}$ em imersão por 10 minutos, cortadas em fatias e separadas nas porções: casca, polpa, fiapos e sementes. Em seguida, as sementes foram submetidas aos seguintes processamentos, em quatro repetições cada: a) cruas (forma natural); b) cozidas em água em ebulição (AE), na proporção de 1:5 (massa das sementes em g/volume de água destilada em $\mathrm{mL}$ ) por 3 tempos: 5, $10 \mathrm{e}$ 15 minutos; c) cozidas no vapor por 10 minutos.

As sementes cruas e cozidas foram congeladas em nitrogênio líquido, liofilizadas até peso constante e trituradas em moinho com peneira de 40 mesh. A farinha de sementes de abóbora (FSA) foi armazenada em frascos de vidro hermeticamente fechados, em temperatura ambiente, até a realização das análises descritas a seguir.

\subsection{Análises químicas}

\section{Composição centesimal}

A umidade das sementes cruas foi determinada pelo aquecimento em estufa a $100-105^{\circ} \mathrm{C}$ até massa constante (AOAC, 1995). O método de Kjeldahl foi usado para dosar a proteína bruta na FSA (AOAC, 1995), sendo o fator de correção 5,4 (PEREIRA et al., 1985) aplicado aos dados para converter o nitrogênio total da amostra em nitrogênio proteico. $\mathrm{O}$ teor de fibra alimentar total foi quantificado por método gravimétrico-enzimático (AOAC, 1995). O nível de extrato etéreo foi dosado por processo gravimétrico (AOAC, 1995), enquanto que a análise de cinzas consistiu na incineração da FSA a $515-550^{\circ} \mathrm{C}$, determinando-se a porcentagem do resíduo (AOAC, 1995).

\section{Minerais}

Os teores dos macrominerais ( $\mathrm{S}, \mathrm{P}, \mathrm{Mg}, \mathrm{Ca}$ e $\mathrm{K}$ ) e microminerais $(\mathrm{Cu}, \mathrm{Zn}, \mathrm{Mn}$ e $\mathrm{Fe})$ foram determinados segundo Malavolta, Vitti e Oliveira (1997). Os extratos foram obtidos por digestão nitroperclórica. $\mathrm{O} S \mathrm{e}$ o $\mathrm{P}$ foram determinados por colorimetria; $\mathrm{Mg}, \mathrm{Ca}, \mathrm{Cu}, \mathrm{Zn}, \mathrm{Mn}$ e Fe por espectrofotometria de absorção atômica; e K por fotometria de chama.

\subsection{Propriedades funcionais}

Para a determinação da absorção de água e óleo, volume de espuma e estabilidade de emulsão, as FSA foram homogeneizadas utilizando-se o equipamento mixer Robot Classic da marca Mallory em sua velocidade máxima.

\section{Solubilidade do nitrogênio}

A FSA foi suspensa em água destilada, ajustando-se o $\mathrm{pH}$ em $2,3,4,5,6,7,8$ e 9 com solução de $\mathrm{HCl}$ ou $\mathrm{NaOH}$. Após o ajuste de $\mathrm{pH}$, as amostras foram submetidas à agitação horizontal por 45 minutos, em temperatura ambiente. Posteriormente, foram centrifugadas a $9750 \times \mathrm{g} / 10$ minutos, e o sobrenadante foi dosado segundo o método de Kjeldahl (BEUCHAT, 1977).

\section{Absorção de água e óleo}

A FSA foi suspensa em água ou óleo, homogeneizada com mixer por 60 segundos e, em seguida, centrifugada a $2000 \times \mathrm{g} / 10$ minutos. $\mathrm{O}$ volume do sobrenadante foi medido e a quantidade de água ou óleo absorvida foi multiplicada por sua respectiva densidade para a conversão em gramas (OKEZIE; BELLO, 1988).

\section{Volume de espuma}

A FSA foi suspensa em água destilada e homogeneizada com mixer por 3,5 minutos. Posteriormente, a mistura foi transferida para uma proveta na qual foram determinados os volumes de espuma em diferentes tempos (0, 30, 60 e 120 minutos após o 
término da agitação por 3,5 minutos). O volume da espuma que permaneceu ao longo do tempo foi calculado considerando-se $100 \%$ o volume de espuma determinado no tempo zero (WANG, CABALLERO-CORBOBA; SGARBIERI, 1992).

\section{Estabilidade de emulsão}

A FSA foi dispersa em água destilada e o óleo foi adicionado aos poucos, sob agitação moderada pelo mixer, por 30 segundos. Em seguida, a solução foi agitada por mais 60 segundos para homogeneizar o sistema. O homogeneizado foi transferido para uma proveta e a mudança volumétrica da espuma, do óleo e da fase aquosa, foi determinada após 0,5; 2,0 e 6,0 horas (OKEZIE; BELLO, 1988).

\subsection{Análises estatísticas}

O experimento foi realizado em delineamento estatístico inteiramente casualizado (DIC), com cinco processamentos e quatro repetições. Os dados foram submetidos à análise de variância e, quando significativa, o teste de Tukey foi usado para as comparações das médias entre os processamentos, a $5 \%$ de probabilidade.

A análise de solubilidade do nitrogênio foi realizada em DIC, em esquema fatorial $5 \times 8$, ou seja, cinco processamentos e oito valores de $\mathrm{pH}$, com quatro repetições. Os dados foram submetidos à análise de variância e, quando significativa, o teste de Tukey foi usado para as comparações das médias entre os processamentos, a $5 \%$ de probabilidade. A fonte de variação $\mathrm{pH}$ foi analisada estatisticamente empregando-se modelos de regressão.

A análise da estabilidade de emulsão foi realizada em DIC, com quatro repetições, sendo os tratamentos dispostos no esquema de parcelas divididas no tempo com os processamentos na parcela e os tempos após agitação nas subparcelas. Foi avaliada a variação dos volumes de espuma, óleo e fase aquosa ao longo do tempo $(0,5 ; 2,0$ e 6,0 horas $)$. Os dados foram submetidos à análise de variância e, quando significativa para os tipos de processamentos, o teste de Tukey foi usado para as comparações das médias, a 5\% de probabilidade, enquanto que, para as comparações entre os tempos após agitação, foi utilizada a análise de regressão (GOMES, 1990).

Todas as análises estatísticas foram feitas com o uso do software SISVAR 4.6.

\section{Resultados e discussão}

O teor de umidade determinado nas sementes cruas, em média, foi de $56,54 \mathrm{~g} .100 \mathrm{~g}^{-1} \pm 0,66$. Os níveis médios (em g. $100 \mathrm{~g}^{-1}$ de matéria seca - MS) de proteína bruta, fibra alimentar, extrato etéreo e cinzas da FSA submetidas a vários processamentos foram de 29,54; 22,40; 36,41 e 3,48, respectivamente. A análise de variância, a $5 \%$ de probabilidade pelo teste de $\mathrm{F}$, mostrou que não houve diferença significativa nos níveis desses nutrientes entre os diferentes processamentos.

Segundo Mesquita et al. (2007), o teor de proteína bruta em 21 linhagens de feijão cru (Phaseolus vulgaris L.) variou de 22,34 a 36,28 g.100 g-1 MS. Portanto, conclui-se que a FSA apresentou nível de proteína bruta próximo ao valor médio dos feijões, o qual representa a principal fonte de proteínas para as populações de baixa renda. Isso significa, do ponto de vista quantitativo, que as sementes da moranga apresentam teor de proteína bruta relevante, podendo ser utilizadas como um alimento fornecedor de proteína. Entretanto, não se deve deixar de considerar a qualidade da proteína presente na dieta.

O teor médio de fibra alimentar determinado na FSA deste trabalho (9,73 g.100 $\mathrm{g}^{-1}$ em matéria fresca - MF) é superior ao nível registrado para a farinha de sementes da abóbora Cucurbita moschata (7,30 g.100 g-1 MF); semelhante ao da farinha de aveia (10,26 g.100 g-1 MF); e inferior ao do farelo de arroz (24,34 g.100 $\mathrm{g}^{-1} \mathrm{MF}$ ) (USP, 2008). O consumo de fibra total recomendado para indivíduos acima de 19 anos é de 21 a 38 g.dia $^{-1}$ (INSTITUTE OF MEDICINA, 2002). Portanto, as sementes da moranga apresentam teor de fibra alimentar significativo, com potencial para serem incorporadas em produtos tais como os lights e dietéticos a base de fibras e para participar da dieta desempenhando papéis fisiológicos importantes. Cerqueira et al. (2008) avaliaram o efeito da farinha de sementes da moranga sobre o metabolismo glicídico e lipídico em ratos e concluíram que sua utilização durante 10 dias diminuiu significantemente os níveis de glicose e triglicerídeos séricos. Tais pesquisadores atribuíram esse resultado ao elevado teor de fibra alimentar presente nas sementes de abóbora.

A FSA apresentou alto teor de extrato etéreo, o qual não foi alterado pelos processamentos. As indicações do uso do óleo extraído das sementes de abóbora envolvem o cozimento de alimentos, incorporação em produtos para temperar saladas e a fabricação de margarinas (EL-ADAWY; TAHA, 2001a). Segundo o sumarizado por Applequist et al. (2006), o teor de ácido linoleico nas sementes de moranga é alto (43,09 a 50,31\% do conteúdo lipídico), o que indica que a FSA apresenta teor lipídico nutritivo já que esse ácido graxo essencial é capaz de reduzir os níveis de colesterol sérico. No entanto, é importante ressaltar que doses excessivas de lipídios devem ser evitadas, pois podem acarretar doenças crônicas tais como diabetes, derrame cerebral, câncer e doenças cardiovasculares.

Quanto à análise de cinzas, o teor médio determinado na FSA (3,48 g.100 g-1 MS) é muito próximo dos valores descritos em outros trabalhos com as sementes da moranga: 3,60 g.100 g-1 MS (AMOO et al., 2004) e 3,45 g.100 g' $\mathrm{gS}^{-1}$ (DEL-VECHIO, 2004).

$\mathrm{Na}$ Tabela 1 constam os teores de macrominerais (S, P, Mg, Ca e K) e microminerais ( $\mathrm{Cu}, \mathrm{Zn}, \mathrm{Mn}$ e Fe) da FSA submetidas a vários processamentos. Não houve diferença significativa na análise de variância, a $5 \%$ de probabilidade pelo teste de $\mathrm{F}$, para os níveis de S, P, Mg, Ca, Cu e Zn. Entretanto, segundo a análise de variância a $1 \%$ de probabilidade pelo teste $\mathrm{F}$, houve diferença significativa para os níveis de $\mathrm{K}, \mathrm{Mn}$ e Fe.

$\mathrm{O}$ cozimento em AE acarretou redução do nível de $\mathrm{K}$ em aproximadamente $14,28 \%$, provavelmente devido à solubilidade desse mineral em água. Os cozimentos no vapor e em AE diminuíram os teores de Mn e Fe em aproximadamente 
Tabela 1. Teores médios ${ }^{\star}$ de macro e microminerais, em matéria seca, da farinha de sementes de abóbora submetidas a vários processamentos.

\begin{tabular}{|c|c|c|c|c|c|c|c|c|c|}
\hline \multirow[b]{3}{*}{ Processamentos } & \multicolumn{5}{|c|}{ Macrominerais } & \multicolumn{4}{|c|}{ Microminerais } \\
\hline & \multicolumn{5}{|c|}{ g. $100 \mathrm{~g}^{-1}$} & \multicolumn{4}{|c|}{ mg.kg-1 } \\
\hline & $S$ & $\mathrm{P}$ & $\mathrm{Mg}$ & $\mathrm{Ca}$ & $\mathrm{K}$ & $\mathrm{Cu}$ & $\mathrm{Zn}$ & $\mathrm{Mn}$ & $\mathrm{Fe}$ \\
\hline Cruas & $0,27 \pm 0,02^{\mathrm{a}}$ & $0,84 \pm 0,03^{\mathrm{a}}$ & $0,36 \pm 0,01^{\mathrm{a}}$ & $0,05 \pm 0,03^{\mathrm{a}}$ & $0,71 \pm 0,03^{\mathrm{a}}$ & $15,95 \pm 0,49^{\mathrm{a}}$ & $64,60 \pm 2,30^{\mathrm{a}}$ & $54,27 \pm 1,46^{\mathrm{a}}$ & $97,50 \pm 4,32^{\mathrm{a}}$ \\
\hline $\begin{array}{l}\text { Cozidas em AE } \\
\text { por } 5 \text { minutos }\end{array}$ & $0,26 \pm 0,02^{\mathrm{a}}$ & $0,85 \pm 0,01^{a}$ & $0,36 \pm 0,02^{a}$ & $0,03 \pm 0,03^{a}$ & $0,60 \pm 0,03^{b}$ & $15,70 \pm 0,59^{\mathrm{a}}$ & $66,27 \pm 0,64^{\mathrm{a}}$ & $51,55 \pm 1,33^{b}$ & $91,35 \pm 2,05^{\mathrm{b}}$ \\
\hline $\begin{array}{l}\text { Cozidas em } \mathrm{AE} \\
\text { por } 10 \text { minutos }\end{array}$ & $0,29 \pm 0,02^{\mathrm{a}}$ & $0,85 \pm 0,01^{\mathrm{a}}$ & $0,36 \pm 0,01^{a}$ & $0,05 \pm 0,01^{\mathrm{a}}$ & $0,60 \pm 0,03^{b}$ & $15,85 \pm 0,33^{\mathrm{a}}$ & $66,45 \pm 0,54^{a}$ & $51,55 \pm 1,17^{b}$ & $89,67 \pm 0,54^{\mathrm{bc}}$ \\
\hline $\begin{array}{l}\text { Cozidas no } \\
\text { vapor por } 10 \\
\text { minutos }\end{array}$ & $0,27 \pm 0,02^{\mathrm{a}}$ & $0,85 \pm 0,02^{\mathrm{a}}$ & $0,36 \pm 0,01^{a}$ & $0,03 \pm 0,01^{\mathrm{a}}$ & $0,69 \pm 0,01^{\mathrm{a}}$ & $16,07 \pm 0,78^{\mathrm{a}}$ & $65,07 \pm 1,05^{a}$ & $49,40 \pm 0,42^{\mathrm{b}}$ & $87,47 \pm 1,22^{\mathrm{bc}}$ \\
\hline Médias & 0,27 & 0,84 & 0,36 & 0,04 & - & 15,88 & 65,28 & - & - \\
\hline CV (\%) & 6,24 & 2,31 & 3,31 & 34,50 & 3,86 & 4,60 & 1,93 & 2,37 & 2,84 \\
\hline
\end{tabular}

${ }^{*}$ Médias de quatro repetições \pm desvio padrão seguidas da mesma letra não diferem entre si (Teste de Tukey p $\leq 0,05$ ). AE: água em ebulição.

7,06 e 9,28\%, respectivamente. Portanto, as sementes cruas apresentaram os níveis mais elevados de Mn e Fe.

Segundo as recomendações de ingestão diária de minerais para indivíduos acima de 19 anos citadas por Franco (2005), a semente da moranga pode ser boa fonte de S, P, Mg e Mn (o consumo de aproximadamente 119 g.dia ${ }^{-1}$ da FSA é suficiente para atingir os níveis médios exigidos para esses minerais) e uma fonte alternativa e/ou complementar para o $\mathrm{Cu}$, Fe e $\mathrm{Zn}$ (a ingestão média precisa ser de aproximadamente 206 g.dia ${ }^{-1}$ da FSA). Quanto ao Ca e K, os teores determinados na FSA foram baixos. Por serem nutrientes amplamente distribuídos em vários alimentos, a utilização das sementes de moranga como fonte de Ca e K não é indicada.

As curvas representativas dos valores da solubilidade do nitrogênio da FSA submetidas a vários processamentos são mostradas na Figura 1. Pelo teste de F a 5\% de probabilidade, verificou-se que variações no $\mathrm{pH}$ acarretaram variações na solubilidade.

A variação do pH afeta o caráter iônico dos grupos ionizáveis dos aminoácidos, provocando alteração nas interações entre eles e, consequentemente, modificando a estrutura tridimensional das proteínas. Como a solubilidade é dependente da conformação da molécula, alterações no $\mathrm{pH}$ afetam a solubilidade do nitrogênio. Para todos os processamentos, o $\mathrm{pH} 3$ acarretou a menor solubilidade do nitrogênio e o $\mathrm{pH} 9$ a maior. O ponto isoelétrico das proteínas vegetais está entre o pH 3 e 5, portanto, justifica-se a baixa solubilidade encontrada no $\mathrm{pH}$ 3. Já a maior solubilidade no $\mathrm{pH} 9$ pode ser explicada pelo fato deste $\mathrm{pH}$ estar mais distante do ponto isoelétrico. De um modo geral, a solubilidade do nitrogênio é mínima no $\mathrm{pH}$ isoelétrico e aumenta em $\mathrm{pH}$ distante do ponto isoelétrico, independente do processamento. Semelhante ao observado neste trabalho, Modesti et al. (2007) concluíram que a menor solubilidade do nitrogênio na farinha de folhas de mandioca foi entre os $\mathrm{pH} 3$ e 5, enquanto que a maior foi determinada no pH 9. Nos pH 2, 3, 7, 8 e 9, as sementes cruas apresentaram a maior solubilidade quando comparadas com as sementes

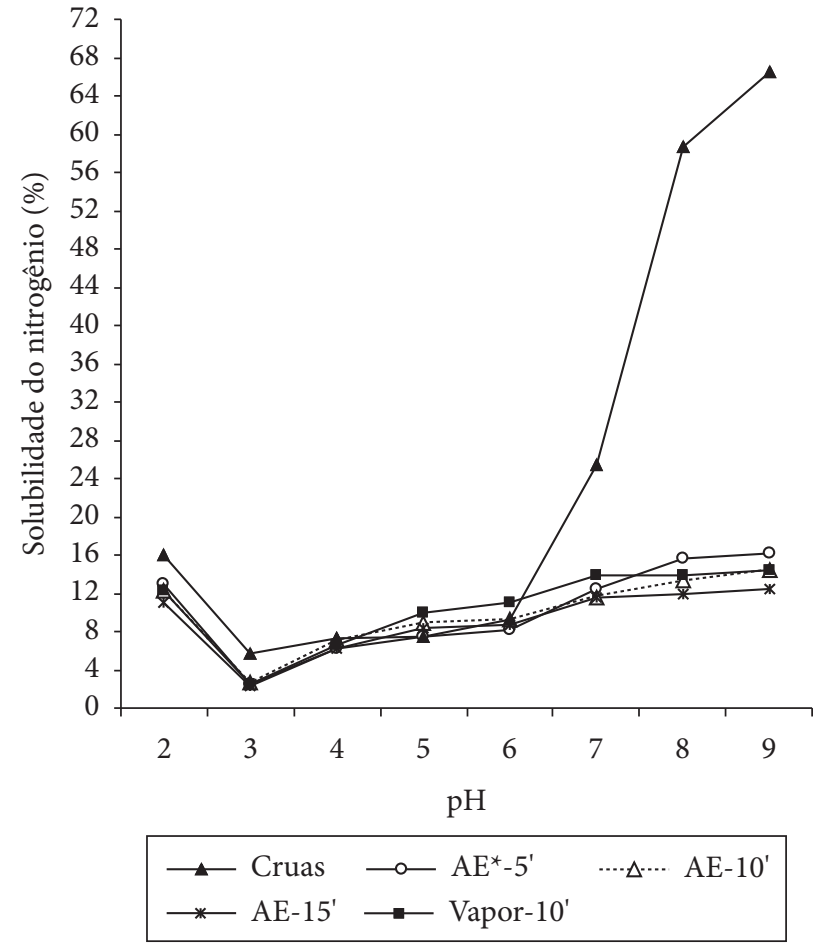

Figura 1. Curvas representativas dos valores da solubilidade do nitrogênio, em diferentes $\mathrm{pH}$, da farinha de sementes de abóboras submetidas a vários processamentos. ${ }^{\star} \mathrm{AE}-5$ '/AE-10'/AE-15': sementes cozidas em água em ebulição por 5, 10 e 15 minutos, respectivamente.

cozidas. Portanto, para tais valores de $\mathrm{pH}$ o cozimento parece ter interferido negativamente. Uma possível explicação para o fato é que a solubilidade pode ter diminuído em consequência da desnaturação das proteínas, provocada pelo tratamento térmico. Nos pH 4, 5 e 6, o tratamento térmico não acarretou diferenças significativas na solubilidade do nitrogênio. 
As porcentagens médias de absorção de água e óleo da FSA submetidas a vários processamentos foram de 154,64 e 573,96\%, respectivamente. A análise de variância, a $5 \%$ de probabilidade pelo teste de F, mostrou que não houve diferença significativa, entre os processamentos, para esses parâmetros. A absorção de óleo nas sementes de abóbora foi maior do que a determinada na farinha de folhas de mandioca (MODESTI et al., 2007), semelhante aos níveis descritos para a soja e farinha de trigo, e menor do que o observado nas farinhas de girassol, algodão e feijão (LIN; HUMBERT, 1974). A absorção de óleo foi maior que a absorção de água, possivelmente devido à presença de maior número de grupos hidrofóbicos na FSA capazes de ligarse ao óleo (LAZOS, 1992). Sathe e Salunkhe (1981) relataram que as globulinas absorvem menos água que as albuminas, portanto, uma explicação complementar dos resultados obtidos fundamenta-se na presença de altos níveis de globulinas nas sementes de abóbora (PEREIRA et al., 1985). A FSA apresenta boa capacidade de absorção de óleo e pode, provavelmente, ser utilizada como ingrediente na formulação e processamento de alimentos que requeiram essa característica.

O tratamento térmico não acarretou diferenças significativas no volume de espuma, a $5 \%$ de probabilidade pelo teste de $\mathrm{F}$. Aos 30 minutos após agitação em alta velocidade, houve uma permanência de apenas $32,97 \%$ do volume da espuma inicial, sendo essa porcentagem correspondente à aproximadamente 0,66 mL de espuma. Aos 60 minutos após o término da agitação já não havia mais espuma, o que indica que a espuma formada pela FSA é pouco estável e, portanto, não apresenta boas características espumantes. Segundo Fennema (1993), a presença de lipídios em excesso pode reduzir a formação e a estabilidade de espuma devido à alteração da expansão da proteína à interface e enfraquecimento ou rompimento das forças coesivas necessárias entre a camada de proteína em torno dos glóbulos de ar, tendo por consequência o colapso de espuma. Como o teor de lipídio na FSA é alto, esta pode ser uma provável explicação para os baixos resultados observados. A estabilidade é importante em formulações em que se requeira a formação de espuma, como suspiros, merengues, musses e bolos (OKEZIE; BELLO, 1988; FENNEMA, 1993).

Para a estabilidade de emulsão, os volumes médios de espuma, de óleo e da fase aquosa da FSA submetidas a vários processamentos são apresentados na Tabela 2. Segundo a análise de variância, o teste de $\mathrm{F}$ foi não significativo a $5 \%$ de probabilidade. Portanto, os processamentos não diferiram entre si quanto às fases observadas na análise de estabilidade de emulsão.

Tabela 2. Estabilidade de emulsão: volumes médios de espuma, óleo e fase aquosa nos tempos: 0,5; 2,0 e 6,0 horas após agitação da farinha de sementes de abóbora submetidas a vários processamentos.

\begin{tabular}{cccc}
\hline \multirow{2}{*}{$\begin{array}{c}\text { Tempo após agitação } \\
\text { (horas) }\end{array}$} & \multicolumn{3}{c}{ Volumes médios $(\mathrm{mL})$} \\
\cline { 2 - 4 } & Espuma & Óleo & Fase aquosa \\
\hline 0,5 & 2,00 & 12,00 & 11,00 \\
2,0 & 1,48 & 12,00 & 11,50 \\
6,0 & 0,00 & 12,50 & 12,50 \\
\hline
\end{tabular}

Todavia, quando se analisa a estabilidade de cada fase (espuma, óleo e água) em função do tempo após agitação, observa-se que, com o decorrer do tempo, houve redução do volume de espuma e pequeno aumento do volume de água. A quantidade de óleo se manteve constante até 2 horas após a agitação da FSA, ocorrendo um pequeno aumento no volume de óleo a partir desse momento. Portanto, a FSA apresentou baixa estabilidade de emulsão, pois, com apenas 0,5 hora após a agitação das amostras, as fases água e óleo já estavam quase completamente separadas. Constata-se que há uma grande dificuldade em se comparar os resultados determinados neste trabalho com os citados na literatura devido à falta de padronização da metodologia e das condições para se obter as características de emulsão, pois elas estão associadas à influência de diversos fatores como $\mathrm{pH}$, temperatura, tipo e geometria de aparelho utilizado, velocidade de adição de óleo e propriedades emulsificantes das proteínas (FENNEMA, 1993).

De modo geral, a forma de avaliação e a determinação das propriedades funcionais são muito diferentes, não havendo ainda uma padronização única das metodologias utilizadas, o que dificulta a comparação dos dados.

\section{Conclusões}

As diferentes formas de cozimento das sementes da moranga não acarretam alterações na composição centesimal. Entretanto, o cozimento em água em ebulição por 5, 10 e 15 minutos reduziu os níveis de $\mathrm{K}, \mathrm{Mn}$ e Fe, além do cozimento no vapor também ter acarretado redução nos níveis de $\mathrm{Mn}$ e Fe.

O cozimento acarreta redução da solubilidade do nitrogênio nos $\mathrm{pH}$ 2, 3, 7, 8 e 9. A farinha de sementes de abóbora apresentou pobre característica espumante e baixa estabilidade de emulsão e capacidade de absorção de água. Entretanto, apresentou boa capacidade de absorção de óleo. Portanto, a farinha de sementes da abóbora Cucurbita maxima apresenta potencial para ser incorporada, provavelmente, em produtos alimentícios que requeiram elevada taxa de absorção de óleo.

Entretanto, não se deve deixar de ressaltar que estudos antinutricionais e toxicológicos das sementes da moranga são importantes para assegurar seu consumo.

\section{Agradecimento}

À FAPEMIG (Fundação de Amparo à Pesquisa do Estado de Minas Gerais) pela concessão do auxílio à pesquisa e da bolsa de iniciação científica (Processo nº CAG-1142/03).

\section{Referências bibliográficas}

AMOO, I. A. et al. Characterization of oil extracted from gourd (Cucurbita maxima) seed. Journal of Food Agriculture and Environment, v. 2, n. 2, p. 38-39, 2004.

APPLEQUIST, W. L. et al. Comparative fatty acid content of seeds of four Cucurbita species grown in a common (shared) garden. Journal of Food Composition and Analysis, v. 19, n. 6-7, p. 606-611, 2006.

ASSOCIAÇÃO BRASILEIRA DE HORTICULTURA - ABH. Disponível em: <http://www.abhorticultura.com.br> Acesso em: 21 jan. 2008. 
ASSOCIATION OF OFFICIAL ANALYTICAL CHEMISTRY - AOAC. Official methods of analysis of the AOAC. 16 ed. Washington, 1995.

BEUCHAT, L. R. Functional and eletrophoretic characteristics of succinylated peanut flour protein. Journal of Agricultural and Food Chemistry, v. 25, n. 2, p. 258-261, 1977.

CERQUEIRA, P. M. et al. Efeito da farinha de semente de abóbora (Cucurbita maxima, L.) sobre o metabolismo glicídico e lipídico em ratos. Revista de Nutrição, v. 21, n. 2, p. 129-136, 2008.

CRUZ, R. C. B. et al. Toxicity evaluation of Cucurbita maxima seed extract in mice. Pharmaceutical Biology, v. 44, n. 4, p. 301-303, 2006.

DEL-VECHIO, G. Efeito do processamento em sementes de abóbora (Cucurbita spp.) sobre os níveis de nutrientes e antinutrientes, Lavras, 2004. 80 p. Dissertação (Mestrado em Agroquímica e Agrobioquímica) - Universidade Federal de Lavras-UFLA.

EL-ADAWY, T. A.; TAHA, K. M. Characteristics and composition of different seed oils and flours. Food Chemistry, v. 74, n. 1, p. 47-54, 2001a.

EL-ADAWY, T. A.; TAHA, K. M. Characteristics and composition of watermelon, pumpkin and paprika seed oils and flours. Journal of Agricultural and Food Chemistry, v. 49, n. 3, p. 1253-1259, 2001b.

FENNEMA, O. R. Química de los alimentos. 2 ed. Zaragoza: Acribia, 1993. 1095 p.

FRANCO, G. Tabela de composição química dos alimentos. 9 ed. São Paulo: Atheneu, 2005. 307 p.

GOMES, F. P. Curso de estatística experimental. 13 ed. São Paulo: Nobel, 1990. 468 p.

INSTITUTE OF MEDICINA. Food and nutrition board: dietary reference intakes for energy, carbohydrate, fiber, fat, fat acids, cholesterol, protein and amino acids. Washington, 2002.
LAZOS, E. S. Certain functional properties of defatted pumpkin seed flour. Plant Foods for Human Nutrition, v. 42, n. 3, p. 257-273, 1992.

LAZOS, E. S.; TSAKNIS, J.; BANTE, M. Changes in pumpkin seed oil during heating. Grasas y Aceites, v. 46, n. 4-5, p. 233-239, 1995.

LIN, M. J. Y.; HUMBERT, E. S. Certain functional properties of sunflower meal products. Journal of Food Science, v. 39, n. 2, p. $368-370,1974$.

MALAVOLTA, E.; VITTI, G. C.; OLIVEIRA, S. A. Avaliação do estado nutricional das plantas: princípios e aplicações. 2 ed. Piracicaba: Potafos, 1997. 319 p.

MESQUITA, F. R. et al. Linhagens de feijão (Phaseolus vulgaris L.): composição química e digestibilidade protéica. Ciência e Agrotecnologia, v. 31, n. 4, p. 1114-1121, 2007.

MODESTI, C. F. et al. Caracterização de concentrado protéico de folhas de mandioca obtido por precipitação com calor e ácido. Ciência e Tecnologia de Alimentos, v. 27, n. 3, p. 464-469, 2007.

OKEZIE, B. O.; BELLO, A. B. Physicochemical and functional properties of winged bean flour and isolate compared with soy isolate. Journal of Food Science, v. 53, n. 2, p. 450-454, 1988.

PEREIRA, A. S. et al. Obtenção e caracterização físico-química de um isolado protéico de semente de moranga (Cucurbita maxima, Duchesnne). Boletim da Sociedade Brasileira de Ciência e Tecnologia de Alimentos, v. 19, n. 1, p. 23-34, 1985.

SATHE, S. K.; SALUNKHE, D. K. Solubilization and electrophorectic characterization of the great nothern bean (Phaseolus vulgaris L.) proteins. Journal of Food Science, v. 46, n. 1, p. 82-87, 1981.

UNIVERSIDADE DE SÃO PAULO - USP. Tabela Brasileira de Composição de Alimentos: TBCA. São Paulo, 2008. Disponível em <http://www.fcf.usp.br/tabela>. Acesso em: 03 mar. 2008.

WANG, S. H.; CABALLERO-CORBOBA, G. M.; SGARBIERI, V. C. Propriedades funcionais de misturas de farinhas de trigo e sojadesengordurada, pré-tratada por microondas. Ciência e Tecnologia de Alimentos, v. 12, n. 1, p. 14-25, 1992. 